\title{
Article \\ Microcirculatory Alterations in Critically Ill Patients with COVID-19-Associated Acute Respiratory Distress Syndrome
}

\author{
Umberto Di Dedda, Alice Ascari, Angela Fantinato, Dario Fina, Ekaterina Baryshnikova (1) and Marco Ranucci * \\ Department of Cardiovascular Anesthesia and Intensive Care, IRCCS Policlinico San Donato, Via Morandi 30, \\ 20097 San Donato Milanese, Milan, Italy; umberto.didedda@grupposandonato.it (U.D.D.); \\ alice.ascari@yahoo.it (A.A.); angela.fantinato94@gmail.com (A.F.); dario.fina88@gmail.com (D.F.); \\ ekaterina.baryshnikova@gmail.com (E.B.) \\ * Correspondence: cardioanestesia@virgilio.it
}

Citation: Di Dedda, U.; Ascari, A.; Fantinato, A.; Fina, D.; Baryshnikova, E.; Ranucci, M. Microcirculatory Alterations in Critically Ill Patients with COVID-19-Associated Acute Respiratory Distress Syndrome. J. Clin. Med. 2022, 11, 1032. https:// doi.org/10.3390/jcm11041032

Academic Editor: Anne Chang

Received: 29 December 2021

Accepted: 14 February 2022

Published: 16 February 2022

Publisher's Note: MDPI stays neutral with regard to jurisdictional claims in published maps and institutional affiliations.

Copyright: () 2022 by the authors. Licensee MDPI, Basel, Switzerland. This article is an open access article distributed under the terms and conditions of the Creative Commons Attribution (CC BY) license (https:// creativecommons.org/licenses/by/ $4.0 /)$.

\begin{abstract}
Background: Presently, a number of specific observations have been performed on microcirculatory function in a coronavirus disease-19 (COVID-19) setting. We hypothesized that, in the critically ill, endothelial dysfunction secondary to severe acute respiratory syndrome coronavirus 2 (SARS-CoV-2) infection and the subsequent inflammation and coagulopathy may lead to microcirculatory alterations, further exacerbated by the hypoxemic state. A dysfunctional microcirculation may represent the hidden motor underlying the development of COVID-19's clinical manifestations. Methods: A single center, prospective, observational study. We analyzed bedside sublingual microcirculation in twenty-four consecutive COVID-19-associated acute respiratory distress syndrome (ARDS) patients mechanically ventilated in an Intensive Care Unit (ICU), together with macrohemodynamics, clinical parameters, echocardiography, and laboratory data at a single time-point after ICU admission. All participants were recruited between March and May 2020. Results: The microcirculatory pattern was characterized by increased values of total vessel density and perfused vessel density, a reduced value of proportion of perfused vessels and microvascular flow index, and high values of heterogeneity index. The duration of mechanical ventilation before microcirculation assessment was inversely associated with the proportion of perfused vessels $(p=0.023)$. Within the macro-hemodynamic parameters, the right ventricle end-diastolic diameter was inversely associated with proportion of perfused vessels and microvascular flow index ( $p=0.039$ and 0.014 , respectively) and directly associated with the heterogeneity index $(p=0.033)$. Conclusions: In COVID-19-associated ARDS patients, the microcirculation showed impaired quality of flow parameters coupled with a high vessel density.
\end{abstract}

Keywords: COVID-19; microcirculation; inflammation; endothelial dysfunction; ARDS

\section{Introduction}

The pathophysiology of COVID-19 is still under investigation. Macroscopic clinical features of the SARS-CoV-2 infection, such as the different phenotypes of ARDS or the COVID-19-associated coagulopathy, are relatively well recognized entities, but there is still poor evidence about the micro-level aspects of the disease. COVID-19 is a systemic disease that primarily injures the vascular endothelium, characterized, probably from the early stage, by a disrupted vessel regulation [1].

States of severe inflammation or cardiovascular disease can induce microcirculatory alterations in terms of perfusion patterns, through the damage of cellular sensing mechanisms needed to modulate blood flow [2-6]. The main events underlying microvascular perfusion impairment are inflammation and endothelial activation/dysfunction. Endothelial dysfunction, in particular, is claimed to play a major role through the glycocalyx damage. Glycocalyx breakdown disrupts the natural anti-inflammatory and anti-coagulant properties of the endothelium, and may create a prothrombotic condition triggered by 
platelet adhesion and aggregation, causing altered local perfusion, functional shunting, and consequent tissue dysoxia [7-10].

Therefore, microcirculatory perturbations represent a direct link to organ dysfunction.

It is of importance that changes in microvascular perfusion may occur in the absence of global hemodynamic perturbations (i.e., low blood pressure, low cardiac output, hyperlactatemia), indicating that these alterations are intrinsic to the microcirculation, a condition known as "loss of hemodynamic coherence" [6]. Medical therapies like fluids or vasoactive medications, such as vasopressors, used in states of shock or as reported in COVID-19 ARDS patients [11], can overwhelm endogenous receptor-mediated vessel regulation, further contributing to the loss of hemodynamic coherence. This condition of macro- vs. micro-hemodynamic mismatch is an independent predictor of adverse outcome and organ dysfunction in sepsis and septic shock [7-12].

COVID-19 patients exhibit endothelium alterations in microvasculature which has been advocated to be the cornerstone for the development of vasculopathy, altered pulmonary vasoregulation leading to ventilation-perfusion mismatch, and thrombogenesis, with widespread thrombi generation at micro and macrovascular level in the lung and in other organs [13]. These abnormalities have been associated with a higher mortality rate [14-16].

To date, a number of studies have investigated the sublingual microcirculation in COVID-19 patients [17-23] A first evaluation conducted by Damiani et al. [17] in 12 patients with COVID-19 pneumonia showed that sublingual microvascular capillary densities were inversely correlated with D-dimer levels, suggesting the impact of microthrombosis on the microcirculatory function. In a prospective observational study [20], Kanoore Edul et al. demonstrated that sublingual microcirculation in severe COVID-19-ARDS patients was characterized by decreases in PPV $(0.96 \pm 0.03)$ and flow quality (MFI: $2.79 \pm 0.10$ and red blood cell velocity: $1124 \pm 161 \mu \mathrm{m} / \mathrm{s}$ ) along with high vascular densities (TVD: $21.9 \pm 3.9$ and PVD: $21.0 \pm 3.5 \mathrm{~mm} / \mathrm{mm}^{2}$ ), compared to normal values. In a multicenter study including 38 mechanically ventilated COVID-19 patients with moderate-to-severe ARDS [22], Favaron et al. explored the sublingual microcirculation and found that COVID-19 patients showed elevated values of TVD, FCD, capillary hematocrit, capillary-to-systemic hematocrit ratio, and red blood cell velocity in comparison with the microcirculatory parameters of healthy volunteers. In addition, they reported normal values of PPV. Finally, the authors found increased numbers of leukocytes and red blood cell aggregates in the microcirculation, which are likely related to the virus-induced inflammation and hypercoagulability.

A previous report from our group [24], in combination with the other contributions in the literature, suggests the potential role of micro/macro-aggregate formation inside the pulmonary vasculature within the pattern of ARDS in COVID-19 patients.

The purpose of the present study is to assess sublingual microcirculatory status in COVID-19 ARDS patients admitted to ICU under mechanical ventilation (MV), and explore any relation with macrohemodynamics, respiratory function, and laboratory data.

\section{Materials and Methods}

The present study is part of a wide project (COVID-OMICS) prospectively undertaken at the IRCCS Policlinico San Donato at the beginning of the COVID-19 pandemic. The study was performed in line with the principles of Declaration of Helsinki, and approval was granted by the Local Ethics Committee of San Raffaele Hospital (Code: 75/INT/2020) and registered at clinicaltrials.gov (NCT04441502). All the surviving patients gave a written informed consent. We followed the Strengthening the Reporting of Observational studies in Epidemiology (STROBE) checklist for observational studies (https:/ / www.strobestatement. org/fileadmin/Strobe/uploads/checklists/STROBE_checklist_v4_combined.pdf, accessed on 28 December 2021). 


\subsection{Patients and Measurements}

This prospective, observational study was conducted in the cardiovascular ICU at the IRCCS Policlinico San Donato, Milan, Italy.

We enrolled twenty-four consecutive patients with laboratory-confirmed COVID-19 and who met the Berlin criteria for ARDS, who were admitted to the ICU between March and May, 2020. All patients were sedated, paralyzed, and ventilated in volume-control mode with Maquet Servo-I ventilators.

The study consisted of a single time-point "photograph" of microcirculatory status, respiratory function, hemodynamics, organ function, biochemical profile, infection, and inflammation indices after the admission into the ICU. Due to the patients' variable clinical condition at presentation, the measurements were performed soon after ICU admission and oro-tracheal intubation in some cases, and later in others. The median of MV duration before microcirculation assessment was $44 \mathrm{~h}$ (IQR: 10-118).

General characteristics of the patient population and the dataset of hemodynamic, ventilatory, respiratory function, laboratory, and clinical parameters are presented in Table 1. Laboratory data of organ function, inflammation, and infection indices were acquired at ICU admission and checked daily. All other parameters were continuously monitored and registered, together with sublingual microcirculation assessment, at the moment of the study. Microcirculatory parameters and timing of sidestream dark field (SDF) measurements of the overall patient population are reported in Table 2. Anticoagulation was established according to a local protocol [24], with an aggressive regimen of lowmolecular weight heparin (LMWH): 6000 b.i.d. (8000 IU b.i.d. if body mass index > 35).

Table 1. General characteristics of the patient population $(\mathrm{N}=24)$.

\begin{tabular}{|c|c|}
\hline Variable & Measure \\
\hline Age (years) & $63(58-66)$ \\
\hline Gender male & $22(91.7)$ \\
\hline Weight (kgs) & $85(76-94)$ \\
\hline Body mass index $\left(\mathrm{kg} / \mathrm{m}^{2}\right)$ & $27.7(24.4-31.2)$ \\
\hline $\begin{array}{l}\text { Mechanical ventilation before microcirculation } \\
\text { assessment (hours) }\end{array}$ & $44(10-118)$ \\
\hline Hypertension & $9(37.5)$ \\
\hline Diabetes & $4(16.7)$ \\
\hline Smoking history & $2(8.3)$ \\
\hline Chronic obstructive pulmonary disease & $2(8.3)$ \\
\hline Cardiovascular disease & $3(12.5)$ \\
\hline Chronic kidney failure & $1(4.2)$ \\
\hline Tympanic temperature $\left({ }^{\circ} \mathrm{C}\right)$ & $36.5(36.2-36.9)$ \\
\hline \multicolumn{2}{|c|}{ Drugs at microcirculation assessment } \\
\hline Propofol & $23(95.8)$ \\
\hline Midazolam & $1(4.2)$ \\
\hline Remifentanil & $23(95.8)$ \\
\hline Dexmedetomidine & $2(8.3)$ \\
\hline Anti-viral agents & $8(33.3)$ \\
\hline Antibiotics & $12(50)$ \\
\hline Tocilizumab & $8(33.3)$ \\
\hline Steroids & $20(83.3)$ \\
\hline \multicolumn{2}{|c|}{ Anti-thrombotic drugs at microcirculation assessment } \\
\hline Low molecular weight heparin & $24(100)$ \\
\hline $\mathrm{P}_{2} \mathrm{Y}_{12}$ inhibitors & $11(45.8)$ \\
\hline \multicolumn{2}{|c|}{ Vasoactive drugs } \\
\hline Nor-epinephrine & $3(12.5)$ \\
\hline Epinephrine & $2(8.3)$ \\
\hline Dopamine & $2(8.3)$ \\
\hline
\end{tabular}


Table 1. Cont.

\begin{tabular}{|c|c|}
\hline Variable & Measure \\
\hline \multicolumn{2}{|c|}{ Macro-hemodynamic pattern } \\
\hline Mean arterial pressure $(\mathrm{mmHg})$ & $95(81-107)$ \\
\hline Heart rate (beats/minute) & $82(58-102)$ \\
\hline Central venous pressure (mmHg) & $11(9-13)$ \\
\hline \multicolumn{2}{|c|}{ Echocardiographic parameters } \\
\hline Left ventricular ejection fraction $(\%)$ & $52(45-65)$ \\
\hline Right ventricular end-diastolic diameter (mm) & $34(28-38)$ \\
\hline Tricuspid annular plane systolic excursion (mm) & $20(18-20)$ \\
\hline Systolic pulmonary arterial pressure $(\mathrm{mmHg})$ & $30(25-31)$ \\
\hline \multicolumn{2}{|c|}{ Mechanical ventilation and gas exchange } \\
\hline Tidal volume $(\mathrm{mL})$ & $500(462-557)$ \\
\hline Respiratory rate (cycles/min) & $20(16-22)$ \\
\hline Inspired oxygen fraction & $0.65(0.60-0.84)$ \\
\hline Positive end expiratory pressure $\left(\mathrm{cmH}_{2} \mathrm{O}\right)$ & $12(11-12)$ \\
\hline Plateau pressure $\left(\mathrm{cm} / \mathrm{H}_{2} \mathrm{O}\right)$ & $24(22-26)$ \\
\hline Driving pressure $\left(\mathrm{cm} / \mathrm{H}_{2} \mathrm{O}\right)$ & $12(11-13)$ \\
\hline Arterial blood $\mathrm{pH}$ & $7.39(7.34-7.45)$ \\
\hline Arterial blood $\mathrm{pCO}_{2}, \mathrm{mmHg}$ & $44(41-54)$ \\
\hline Arterial blood $\mathrm{pO}_{2}, \mathrm{mmHg}$ & $91(73-98)$ \\
\hline Arterial blood oxygen saturation (\%) & $96(94-97)$ \\
\hline Arterial $\mathrm{pO}_{2} /$ Inspired $\mathrm{O}_{2}$ fraction & $141 \pm 48$ \\
\hline Central venous blood oxygen saturation (\%) & $78(74-84)$ \\
\hline Arterial blood lactates $(\mathrm{mmol} / \mathrm{L})$ & $1.4(1.2-1.8)$ \\
\hline \multicolumn{2}{|c|}{$\begin{array}{ll}\text { Laboratory values } \\
\end{array}$} \\
\hline White blood cells $(\times 1000 / \mu \mathrm{L})$ & $8.8(6.3-12.3)$ \\
\hline Hemoglobin $(\mathrm{g} / \mathrm{dL})$ & $11(9.8-12.2)$ \\
\hline Platelets $(\times 1000 / \mu \mathrm{L})$ & $264(155-391)$ \\
\hline Serum bilirubin (mg/dL) & $0.53(0.39-0.87)$ \\
\hline Serum creatinine $(\mathrm{mg} / \mathrm{dL})$ & $0.98(0.70-1.15)$ \\
\hline Albumin (mg/dL) & $2.3(2.1-2.8)$ \\
\hline Interleukin-6 (pg/mL) & $112(50-266)$ \\
\hline Prothrombin time (seconds) & $87(81-89)$ \\
\hline Activated partial thromboplastin time (seconds) & $35(30-41)$ \\
\hline Fibrinogen $(\mathrm{mg} / \mathrm{dL})$ & $770(623-873)$ \\
\hline Antithrombin activity (\%) & $92(82-103)$ \\
\hline D-Dimers $(\mu \mathrm{g} / \mathrm{mL})$ & $2.4(1.2-3.8)$ \\
\hline SOFA score (points) & $4(3-4.75)$ \\
\hline
\end{tabular}

Data are number (\%) or median (interquartile range); SOFA: Sequential Organ Failure Assessment.

Table 2. Microcirculatory parameters (compared to normal values) and timing of SDF measurements in the overall patient population $(\mathrm{N}=24)$.

\begin{tabular}{|c|c|c|c|c|}
\hline Microcirculatory Parameters & Value, Median & Value, Mean & $\begin{array}{l}\text { Normal } \\
\text { Values }\end{array}$ & $p$-Value \\
\hline Total vessel density $\left(\mathrm{mm} / \mathrm{mm}^{2}\right)$ & $24.8(21.6-25.8)$ & $23,825 \pm 3.03$ & $16.7 \pm 1.6$ & $<0.0001$ \\
\hline Perfused vessel density $\left(\mathrm{mm} / \mathrm{mm}^{2}\right)$ & $21.6(18.7-23.5)$ & $21.188 \pm 3.6$ & $16.6 \pm 1.6$ & $<0.0001$ \\
\hline Percentage of perfused vessels (\%) & $88.8(86.2-95.3)$ & $89.815 \pm 6.9$ & $100.00 \pm 0.0$ & $<0.0001$ \\
\hline Microvascular flow index (points) & $2.43(2.31-2.69)$ & $2.457 \pm 0.315$ & $2.97 \pm 0.03$ & $<0.0001$ \\
\hline Heterogeneity index (arbitrary units) & $0.41(0.28-0.45)$ & $0.381 \pm 0.148$ & $0.04 \pm 0.03$ & $<0.0001$ \\
\hline Onset of symptoms to exam (days) & $12.5(9.2-15.8)$ & & & \\
\hline Tracheal intubation to exam (hours) & $44(10.2-118)$ & & & \\
\hline
\end{tabular}


The Sequential Organ Failure Assessment (SOFA) score was calculated simultaneously with the study, representing therefore a single time-point image of the degree of organ systems function/dysfunction, coupled with sublingual microcirculatory status.

Microscan (MicroVision Medical, Amsterdam, The Netherlands) was used to obtain sublingual microcirculation data acquiring SDF images.

After carefully removing saliva with gauzes and avoiding suction, the microcirculation was assessed by capturing several consecutive videoclips at different areas of the sublingual mucosa. Prior to analysis, captured videos were selected, four per patient, based on an image quality score (IQS), according to the recommendation by Massey and Shapiro [25].

Each video was subsequently analyzed using the Capillary Mapper 1.4, a recently developed web-based software program (https: / / capillary-mapper.uni-muenster.de, accessed on 28 December 2021), which enables manual analysis to be carried out according to recommendations of the 2018 Consensus [26].

The Capillary Mapper has been successfully validated for manual analyses of microcirculation videos against the current gold standard, the software AVA 3.2 [27].

For determination of total vessel density (TVD), perfused vessel density (PVD), and proportion of perfused vessels (PPV), microvessels were drawn in by hand using a computer mouse. Capillary flow was then classified as absent, intermittent, sluggish, or continuous. The microvascular flow index (MFI quadrant) was taken as the average of the predominant flow in each of the four quadrants in the video. This, in turn, was used to obtain the heterogeneity index (HI), derived taking into account the highest site flow velocity minus the lowest site flow velocity, divided by the mean flow velocity of all sublingual sites. The present study primarily focuses on capillaries and microvessels $(<20 \mu \mathrm{m}$ in diameter) Manual microcirculation analysis was performed by two external independent examiners, who were blinded to the patient identity and clinical condition.

Transthoracic echocardiography was performed by a single expert operator at the moment of the study in order to assess left and right ventricular dimensions, systolic and diastolic function, valvular status, and estimate systolic pulmonary arterial pressure, according to European Society of Echocardiography guidelines [28].

\subsection{Endpoints}

The primary endpoint was to assess the characteristics of sublingual microcirculatory flow in parallel with global hemodynamic status in COVID-19 associated ARDS patients admitted to ICU.

A secondary endpoint was the identification of differences in microcirculatory function between survivors and non-survivors.

\subsection{Statistics}

Sample size was defined according to the secondary hypothesis. We applied a preliminary hypothesis of a $45 \%$ mortality rate, based on the existing Italian and American reports [29,30]. Such mortality rate refers to COVID-19 ARDS patients receiving invasive MV in ICU, namely the most critically ill patient population. By using SDF technology, Edul et al. [31], found that PPV was nearly 88\% (standard deviation 10\%) in septic shock survivors, and we assumed this value for COVID-19 survivors. We hypothesized that non-survivors had a $15 \%$ lower PPV (76\%). With an alpha value of 0.05 and a power of $80 \%$, two groups of 12 patients were needed to confirm the experimental hypothesis.

However, at the beginning of the study we could not anticipate (i) the number of patients admitted to our ICU during the pandemic or (ii) the human resources needed to obtain reliable microcirculatory data, and (iii) no data on microcirculation in COVID-19 was available in literature at the time of investigation. Therefore, this sample size was actually settled during the study period.

Data are presented as number (\%) or median (interquartile range, IQR). Correlations between continuous variables were assessed using correlation coefficients. For all the tests, a two-tailed $p$ value $<0.05$ was considered significant. The statistical analyses were 
conducted using computerized packages (SPPS 13.0, IBM, Chicago, IL, USA, and MedCalc, Ostend, Belgium).

\subsection{Definitions}

Survival was settled at 30 -days from ICU admission. Thromboembolic events were defined on the basis of clinically relevant manifestation and by computerized tomography when available.

\section{Results}

Twenty-four patients were included in the study (median age, 63 years [IQR 58-66], $91,7 \%$ male). The most common comorbidities were hypertension $(37.5 \%)$, diabetes $(16.7 \%)$, and overweightness, with a median body mass index value of $27.7 \mathrm{~kg} / \mathrm{m}^{2}$ [IQR 24.4-31.2] Table 1 presents general, clinical, and laboratory characteristics of the patient population at ICU admission.

Twelve patients $(50 \%)$ died in the ICU, and the others were discharged from the ICU and subsequently from the hospital. Microcirculatory parameters and timing of measurements of the overall patient population are shown in Table 2.

There were some associations between the general clinical profile of the patients and the microcirculatory function. Age was directly associated with TVD $(p=0.038)$ and PVD $(p=0.031)$. None of our series was febrile at the time of the study, nor diagnosed with co-existing bacterial infection. All the patients were intubated and receiving invasive MV before the study for a median period of $44 \mathrm{~h}$ [IQR 10-118]. The time under MV before the microcirculatory assessment was inversely associated with PPV $(p=0.023)$. The majority of our patients suffered from moderate ARDS at the time of microcirculation evaluation, with an arterial $\mathrm{pO}_{2} /$ inspired $\mathrm{O}_{2}$ fraction $(\mathrm{P} / \mathrm{F})$ median value of $141 \pm 48$. Median PEEP levels were $12(11-12) \mathrm{cmH}_{2} \mathrm{O}$. At the time of the study, the criteria of protective invasive mechanical ventilation were met.

No association between MV parameters, gas exchange, and microcirculatory variables was found. Patients were hemodynamically stable with nearly normal lactate (1.4 (1.2-1.8) $\mathrm{mmol} / \mathrm{L})$ and adequate central venous blood oxygen saturation (78\% (74-84)).

No association between coagulation-related parameters (fibrinogen, antithrombin, D-dimer) and microcirculatory variables was found.

Echocardiographic parameters were overall in the normal range, and none of the patients were suffering from cardiac failure or cardiogenic shock at the time of microcirculation assessment. Within the macro-hemodynamic parameters, only the right ventricle end-diastolic diameter (RVEDD) was inversely associated with PPV and MFI ( $p=0.039$ and 0.004 , respectively) and directly associated with the HI $(p=0.033)$. The SOFA score was not associated with any of the microcirculation parameters.

Compared to reported normal values [20,31], the microcirculatory pattern was characterized by increased values of TVD and PVD, a reduced value of PPV $(<90 \%)$, decreased values of MFI below the cut-off value of 2.6 in 17 patients (71\%) and high values of $\mathrm{HI}$ (Table 2).

In our study, the sample size was probably too small to explore any relationship with the outcome. Hence, the secondary endpoint was not verifiable.

\section{Discussion}

The results of our study may be summarized as follows: (i) mechanically ventilated COVID-19 patients with associated moderate to severe ARDS showed an altered microcirculatory function after admission in the ICU, characterized by an increased capillary density, a low PPV and MFI, and a high HI; and (ii) the main clinical determinants of microcirculation impairment were the time of MV before the examination, and the right ventricular dysfunction expressed as RVEDD.

Determinants of Microcirculatory Alterations in COVID-19 ARDS Patients 
Our data show a microcirculatory pattern characterized by supra-normal values of TVD and PVD. Multiple mechanisms may underlie these findings. A normal microvascular density might be linked to the progressive loss of vasomotor tone secondary to the blunted sympathetic drive, as happens in the early phase of septic shock, resulting in capillary vasodilation and preserved microvascular perfusion. In this phase, indeed, the microvascular endothelial response to vasodilating stimuli might be relatively preserved.

As a result of the endothelium invasion by SARS-CoV-2 and the consequent systemic increase in pro-inflammatory cytokines, the infection confers a pro-thrombo-inflammatory phenotype to endothelial cells, eliciting progressive inflammation and systemic vascular thrombosis in macro- and microvasculature, interstitial edema, fibrosis, and architectural rearrangements of microvascular beds, including elongation of venules and sprouting neoangiogenesis $[8,32,33]$. In our study, we addressed the hemostatic system by measuring the usual clinical parameters, and we could not find an association with microcirculatory changes. However, COVID-19-induced coagulopathy is a complex entity, involving thrombin generation, platelet activation, and fibrinolysis disturbances. It is possible that more sophisticated markers of the hemostatic system may correlate with microcirculatory function [34].

Besides this, severe COVID-19 patients suffer from hypoxemia. The hypoxemic state is a well-recognized powerful trigger for angiogenesis and capillary recruitment [35,36]. Therefore, the reported increased capillary density is likely to be an adaptive response to hypoxemia, a physiologic compensatory reaction to augment the oxygen-extraction capacity by decreasing diffusion distances in the microcirculation. Lastly, microthrombosis is another well-known stimulus for vascular growth [37], accounting for both the increased capillary density and the impaired microcirculatory flow in our series. In this regard, post-mortem studies from COVID-19 patients revealed regular presence of widespread microthrombosis, capillary congestion, and areas of increased capillary density in different organ systems [38-41].

Our findings are in accordance with recent studies [20,22], while in contrast with others $[17,18]$ reporting decreases in microvascular density in the same setting.

However, our patient population was in more severely hypoxemic conditions $\left(\mathrm{PaO}_{2} / \mathrm{FiO}_{2}\right.$ $141 \pm 48 \mathrm{mmHg})$ than those reported by the cited authors $\left(\mathrm{PaO}_{2} / \mathrm{FiO}_{2} 207 \pm 88 \mathrm{mmHg}\right)$.

This severe hypoxemic state could represent the predominant factor determining vascular adaptive response towards capillary recruitment and/or neoangiogenesis, thus explaining such differences.

Of importance is that the reported microcirculatory compensatory mechanisms to hypoxemia in COVID-19 disagree with the microcirculatory alterations reported in conventional sepsis. During sepsis, indeed, both the components of microcirculatory oxygen delivery (capillary density and quality of flow parameters) are impaired.

Beside the increased microvascular density, which represents the diffusive component of microcirculatory oxygen delivery, our results showed that the convective components (i.e., MFI, PPV) were impaired.

It has been demonstrated that severe sepsis induces marked alterations of microvascular variables of functional perfusion (PPV, MFI) and of heterogeneity of perfusion (HI), and that such alterations are more severe in the earlier than in the later phase of sepsis [12].

Endothelial dysfunction, and the broad spectrum of its manifestations, is a key mechanism underlying sepsis-induced microvascular alterations.

Accumulating evidence indicates that SARS-CoV-2 infection adversely affects the endothelium of the microcirculation by altering the integrity of vessel barrier, inducing endothelial inflammation and promoting a pro-coagulative state $[42,43]$. The peculiar hyperinflammatory and pro-coagulant state of COVID-19 implies a critical role of the vascular endothelium for two main reasons: first, the endothelium is the target organ of SARS-CoV-2, and virus entry and proliferation in endothelial cell directly induces damage and apoptosis [44]. Second, the endothelium is the main effector contributing to the inflammatory process and thrombosis. SARS-CoV-2 may cause endothelial dysfunction directly 
through EC infection, or indirectly through the sustained and exaggerated activation of endothelial cells through a massive pro-inflammatory cytokine release secondary to viral infection [45].

In our COVID-19 series, the reduced blood flow velocity (PPV and MFI) and the increased blood flow heterogeneity $(\mathrm{HI})$ are consistent with the sepsis-induced microcirculatory alterations as described by De Backer et al. [2] and by Edul et al. [31], and are in accordance with a recent study by Rovas et al. [46], where microcirculation was impaired in terms of reduced MFI and PPV in septic patients compared to healthy controls.

In the septic patient, the immediate restoration of a normal microvascular pattern after acetylcholine administration suggests that microthrombi formation is probably not the main determinant of the altered capillary perfusion [2]. Nevertheless, we suspect that in severe COVID-19, as a consequence of the powerful procoagulant state, the widespread microthrombi formation can be tremendous and, thus, may represent the predominant mechanism underlying the impaired microvascular flow in terms of PPV and heterogeneity of perfusion. These changes, indeed, are most likely related to infection-induced thromboinflammation and hypercoagulability.

In parallel, increased HI and reduced PPV reflect the pattern of distributive shock (e.g., sepsis), where vessels plugged by microthrombi are seen next to normally flowing capillaries, representing functional shunting. From a pathophysiological point of view, indeed, the heterogeneity is a key determinant of the shunted fraction, often seen in distributive shock.

The majority of our patients suffered from moderate ARDS at the time of microcirculation assessment. MV-related variables, gas-exchange data, and the lung dysfunction index $\mathrm{PaO}_{2} / \mathrm{FiO}_{2}$ did not show any correlation with the variables of microcirculation.

Interestingly, MV duration before the microcirculation assessment was inversely associated with PPV ( $p=0.023)$. Given the inflammatory nature of COVID-19, it might be expected that a longer duration of MV before microcirculatory assessment may be associated with a more impaired microvascular flow, due to the progression of the inflammation process and/or severity of the COVID-19-associated ARDS phenotype.

Of importance is that microcirculatory alterations were not affected by the global hemodynamic state or the use of adrenergic agents, which was limited to two patients only, and at very low doses.

The observed changes in microcirculation function may be therefore intrinsic to the microvasculature, occurring in the absence of macro-hemodynamic perturbations, as shown in our series, defining a scenario of loss of hemodynamic coherence.

Not surprisingly, indeed, other perfusion-related macrohemodynamic parameters such as lactate, capillary refill time, and central venous oxygen saturation were, on average, in the normal range at the time of microcirculation assessment.

It must be stressed that the aim of the present study was the assessment of microcirculatory function restricted to the early phase of the disease. We did not perform sequential sublingual microcirculation assessments in the more advanced state of the disease. As microcirculation is a dynamic process, more significant microcirculatory abnormalities, compared with baseline, might have then been identified, possibly bringing out any association with improvement or decline of organ function over time.

The impaired microcirculation parameters that we found in our series are then probably to be ascribed to the effects of more aggressive forms of COVID-19, coupled with preexisting patients' individual factors such as cardiovascular disease, diabetes, or obesity, namely conditions of pre-existing endothelial dysfunction. In these cases, apparently, the deleterious effects of inflammation and hypoxia are precociously visible and detectable even at microvascular level.

Regarding the hypothesized prognostic power of microcirculation function in this new setting, we did not find any statistically significant correlation with the SOFA score.

COVID-19 can also cause a wide range of cardiac injury including acute myocardial infarction, stress-related cardiomyopathy, myocarditis, nonischemic myocardial injury due 
to hyperinflammatory cytokine storm, and microvascular dysfunction affecting the left or right ventricle (RV) $[44,47]$. We suspect that the formation of pulmonary microthrombi increases the risk of subsequent RV dysfunction, explaining our finding of impaired RV function in terms of RVEDD in $11(46 \%)$ patients.

Indeed, abnormal RVEDD ( $>34 \mathrm{~mm}$ ) was inversely associated with quality of flow in the sublingual microcirculation (PPV and MFI) and, accordingly, directly associated with an increased heterogeneity of perfusion (HI).

No-one in this series was diagnosed with cardiogenic shock at the time of microcirculation assessment. Nevertheless, similar microvascular alterations have been observed in patients with severe heart failure and are more severe in non-survivors [48,49].

The findings of this study have to be seen in light of some limitations. Due to the peculiar characteristics of this pandemic disease, the complex technology, and the limited human resources, we could include only a limited series of patients. Our sample size is however comparable to what already published.

Furthermore, measurements were taken at a single time point, during the acute phase of a changing clinical course, which does not exclude possible different findings in other stages of the illness. As microcirculation is a dynamic process, further investigation of the microcirculatory function trend, rather than an instant picture, might highlight the progressive changes of microcirculatory function in COVID-19's clinical evolution.

In conclusion, our results show that in moderate to severe COVID-19 ARDS patients, the microcirculation is disturbed in terms of density, perfusion, and flow heterogeneity. The vascular endothelial dysfunction secondary to SARS-CoV-2 infection results in widespread inflammation and coagulopathy, which, together with hypoxemia, lead to various degrees of dysfunction in the microvasculature.

We suspect that, as happens in sepsis, microcirculatory alterations represent the motor of the cascade of events leading to organ dysfunction and bad outcomes. Therefore, besides a solid knowledge of what happens in septic patients, a compelling need for microcirculation monitoring at the bedside in COVID-19 ICU patients is advocated.

Author Contributions: Conceptualization, U.D.D.; Data curation, U.D.D., A.A., A.F., D.F. and E.B.; Formal analysis, U.D.D., A.A., A.F. and D.F.; Funding acquisition, M.R.; Investigation, U.D.D. and D.F.; Methodology, U.D.D. and M.R.; Project administration, E.B.; Supervision, U.D.D., E.B. and M.R.; Validation, U.D.D.; Writing—original draft, U.D.D.; Writing—review and editing, U.D.D. and M.R. All authors have read and agreed to the published version of the manuscript.

Funding: This work was supported by local research funds of the IRCCS Policlinico San Donato, a Clinical Research Institution recognized and partially funded by the Italian Ministry of Health.

Institutional Review Board Statement: The study was performed in line with the principles of Declaration of Helsinki, and approval was granted by the Local Ethics Committee of San Raffaele Hospital (Code: 75/INT/2020) and registered at clinicaltrials.gov (NCT04441502). All the surviving patients gave written informed consent.

Informed Consent Statement: Due to the peculiar characteristics of this pandemic, the emergency conditions, and the difficult logistic circumstances, patient consent was waived at the moment of the examination and subsequently retrieved for the survived patients.

Data Availability Statement: The datasets generated and/or analyzed during the current study are available from the corresponding author on reasonable request.

Acknowledgments: We thank Jessica Zannoni, Giovanni Nava, Gilda Tornatore, Claudio Soru, Vlasta Bari, Mauro Cotza, and Giuseppe Isgrò for their precious help in database compilation and critical support. We thank our cardiovascular intensive care unit nurse staff for their dedication and help in this study, performed under difficult circumstances.

Conflicts of Interest: The authors declare that they have no known competing financial interest or personal relationships that could have appeared to influence the work reported in this paper. 


\section{References}

1. Marini, J.J.; Gattinoni, L. Management of COVID-19 Respiratory Distress. JAMA 2020, 323, 2329-2330. [CrossRef] [PubMed]

2. De Backer, D.; Creteur, J.; Preiser, J.C.; Dubois, M.J.; Vincent, J.L. Microvascular blood flow is altered in patients with sepsis. Am. J. Respir. Crit. Care Med. 2002, 166, 98-104. [CrossRef] [PubMed]

3. De Backer, D.; Ospina-Tascon, G.; Salgado, D.; Favory, R.; Creteur, J.; Vincent, J.L. Monitoring the microcirculation in the critically ill patient: Current methods and future approaches. Intensive Care Med. 2010, 36, 1813-1825. [CrossRef]

4. De Backer, D.; Donadello, K.; Taccone, F.S.; Ospina-Tascon, G.; Salgado, D.; Vincent, J.L. Microcirculatory alterations: Potential mechanisms and implications for therapy. Ann. Intensive Care 2011, 1, 27. [CrossRef] [PubMed]

5. Massey, M.J.; Hou, P.C.; Filbin, M.; Wang, H.; Ngo, L.; Huang, D.T.; Aird, W.C.; Novack, V.; Trzeciak, S.; Yealy, D.M.; et al Microcirculatory perfusion disturbances in septic shock: Results from the ProCESS trial. Crit. Care 2018, 22, 308. [CrossRef]

6. Ince, C. Hemodynamic coherence and the rationale for monitoring the microcirculation. Crit. Care 2015, 19 (Suppl. S3), S8. [CrossRef]

7. Dekker, N.A.M.; Veerhoek, D.; Koning, N.J.; van Leeuwen, A.L.I.; Elbers, P.W.G.; van den Brom, C.E.; Vonk, A.B.A.; Boer, C. Postoperative microcirculatory perfusion and endothelial glycocalyx shedding following cardiac surgery with cardiopulmonary bypass. Anaesthesia 2019, 74, 609-618. [CrossRef]

8. Jacob, M.; Chappell, D.; Becker, B.F. Regulation of blood flow and volume exchange across the microcirculation. Crit. Care 2016, 20, 319. [CrossRef]

9. Koning, N.J.; Atasever, B.; Vonk, A.B.; Boer, C. Changes in microcirculatory perfusion and oxygenation during cardiac surgery with or without cardiopulmonary bypass. J. Cardiothorac. Vasc. Anesth. 2014, 28, 1331-1340. [CrossRef]

10. Marechal, X.; Favory, R.; Joulin, O.; Montaigne, D.; Hassoun, S.; Decoster, B.; Zerimech, F.; Neviere, R. Endothelial glycocalyx damage during endotoxemia coincides with microcirculatory dysfunction and vascular oxidative stress. Shock 2008, 29, 572-576. [CrossRef]

11. Fox, S.; Vashisht, R.; Siuba, M.; Dugar, S. Evaluation and management of shock in patients with COVID-19. Cleve Clin. J. Med. 2020. [CrossRef] [PubMed]

12. De Backer, D.; Donadello, K.; Sakr, Y.; Ospina-Tascon, G.; Salgado, D.; Scolletta, S.; Vincent, J.L. Microcirculatory alterations in patients with severe sepsis: Impact of time of assessment and relationship with outcome. Crit. Care Med. 2013, 41, 791-799. [CrossRef] [PubMed]

13. Pons, S.; Fodil, S.; Azoulay, E.; Zafrani, L. The vascular endothelium: The cornerstone of organ dysfunction in severe SARS-CoV-2 infection. Crit. Care. 2020, 24, 353. [CrossRef]

14. Tang, N.; Li, D.; Wang, X.; Sun, Z. Abnormal coagulation parameters are associated with poor prognosis in patients with novel coronavirus pneumonia. J. Thromb. Haemost. 2020, 18, 844-847. [CrossRef] [PubMed]

15. Guan, W.J.; Ni, Z.Y.; Hu, Y.; Liang, W.H.; Ou, C.Q.; He, J.X.; Liu, L.; Shan, H.; Lei, C.L.; Hui, D.S.C.; et al. China Medical Treatment Expert Group for COVID-19. Clinical Characteristics of Coronavirus Disease 2019 in China. New Engl. J. Med. 2020, 382, 1708-1720. [CrossRef] [PubMed]

16. Zhou, F.; Yu, T.; Du, R.; Fan, G.; Liu, Y.; Liu, Z.; Xiang, J.; Wang, Y.; Song, B.; Gu, X.; et al. Clinical course and risk factors for mortality of adult inpatients with COVID-19 in Wuhan, China: A retrospective cohort study. Lancet 2020, 395, 1054-1062. [CrossRef]

17. Damiani, E.; Carsetti, A.; Casarotta, E.; Scorcella, C.; Domizi, R.; Adrario, E.; Donati, A. Microvascular alterations in patients with SARS-COV-2 severe pneumonia. Ann. Intensive Care 2020, 10, 60. [CrossRef] [PubMed]

18. Carsetti, A.; Damiani, E.; Casarotta, E.; Scorcella, C.; Domizi, R.; Montomoli, J.; Gasparri, F.; Gabbanelli, V.; Pantanetti, S.; Carozza, R.; et al. Sublingual microcirculation in patients with SARS-CoV-2 undergoing veno-venous extracorporeal membrane oxygenation. Microvasc. Res. 2020, 132, 104064. [CrossRef]

19. do Espírito Santo, D.A.; Lemos, A.C.B.; Miranda, C.H. In vivo demonstration of microvascular thrombosis in severe COVID-19. J. Thromb. Thrombolysis 2020, 50, 790-794. [CrossRef]

20. Kanoore Edul, V.S.; Caminos Eguillor, J.F.; Ferrara, G.; Estenssoro, E.; Siles, D.S.P.; Cesio, C.E.; Dubin, A. Microcirculation alterations in severe COVID-19 pneumonia. J. Crit. Care 2021, 61, 73-75. [CrossRef]

21. Rovas, A.; Osiaevi, I.; Buscher, K.; Sackarnd, J.; Tepasse, P.R.; Fobker, M.; Kühn, J.; Braune, S.; Göbel, U.; Thölking, G.; et al. Microvascular dysfunction in COVID-19: The MYSTIC study. Angiogenesis 2021, 24, 145-157. [CrossRef] [PubMed]

22. Favaron, E.; Ince, C.; Hilty, M.P.; Ergin, B.; van der Zee, P.; Uz, Z.; Wendel Garcia, P.D.; Hofmaenner, D.A.; Acevedo, C.T.; van Boven, W.J.; et al. Capillary Leukocytes, Microaggregates, and the Response to Hypoxemia in the Microcirculation of Coronavirus Disease 2019 Patients. Crit. Care Med. 2021, 49, 661-670. [CrossRef] [PubMed]

23. Abou-Arab, O.; Beyls, C.; Khalipha, A.; Guilbart, M.; Huette, P.; Malaquin, S.; Lecat, B.; Macq, P.Y.; Roger, P.A.; Haye, G.; et al. Microvascular flow alterations in critically ill COVID-19 patients: A prospective study. PLoS ONE 2021, 16, e0246636. [CrossRef] [PubMed]

24. Ranucci, M.; Ballotta, A.; Di Dedda, U.; Bayshnikova, E.; Dei Poli, M.; Resta, M.; Falco, M.; Albano, G.; Menicanti, L. The procoagulant pattern of patients with COVID-19 acute respiratory distress syndrome. J. Thromb. Haemost. 2020, 18, 1747-1751. [CrossRef]

25. Massey, M.J.; Shapiro, N.I. A guide to human in vivo microcirculatory flow image analysis. Crit. Care 2016, 20, 35. [CrossRef] 
26. Ince, C.; Boerma, E.C.; Cecconi, M.; De Backer, D.; Shapiro, N.I.; Duranteau, J.; Pinsky, M.R.; Artigas, A.; Teboul, J.L.; Reiss, I.K.M.; et al. Cardiovascular Dynamics Section of the ESICM. Second consensus on the assessment of sublingual microcirculation in critically ill patients: Results from a task force of the European Society of Intensive Care Medicine. Intensive Care Med. 2018, 44, 281-299. [CrossRef]

27. Hessler, M.; Arnemann, P.H.; Zamit, F.; Seidel, L.; Kampmeier, T.G.; Kathöfer, U.; Morelli, A.; Ince, C.; Rehberg, S.W.; Ertmer, C. A new complimentary web-based tool for manual analysis of microcirculation videos: Validation of the Capillary Mapper against the current gold standard AVA 3.2. Microcirculation 2018, 25, e12505. [CrossRef]

28. Rudski, L.G.; Lai, W.W.; Afilalo, J.; Hua, L.; Handschumacher, M.D.; Chandrasekaran, K.; Solomon, S.D.; Louie, E.K.; Schiller, N.B. Guidelines for the echocardiographic assessment of the right heart in adults: A report from the American Society of Echocardiography endorsed by the European Association of Echocardiography, a registered branch of the European Society of Cardiology, and the Canadian Society of Echocardiography. J. Am. Soc. Echocardiogr. 2010, 23, 685-713. [CrossRef]

29. Grasselli, G.; Greco, M.; Zanella, A.; Albano, G.; Antonelli, M.; Bellani, G.; Bonanomi, E.; Cabrini, L.; Carlesso, E.; Castelli, G.; et al COVID-19 Lombardy ICU Network. Risk Factors Associated with Mortality Among Patients With COVID-19 in Intensive Care Units in Lombardy, Italy. JAMA Intern. Med. 2020, 180, 1345-1355. [CrossRef]

30. Richardson, S.; Hirsch, J.S.; Narasimhan, M.; Crawford., J.M.; McGinn, T.; Davidson, K.W.; The Northwell COVID-19 Research Consortium; Barnaby, D.P.; Becker, L.B.; Chelico, J.D.; et al. Presenting Characteristics, Comorbidities, and Outcomes Among 5700 Patients Hospitalized With COVID-19 in the New York City Area. JAMA 2020, 323, 2052-2059. [CrossRef]

31. Edul, V.S.; Enrico, C.; Laviolle, B.; Vazquez, A.R.; Ince, C.; Dubin, A. Quantitative assessment of the microcirculation in healthy volunteers and in patients with septic shock. Crit. Care Med 2012, 40, 1443. [CrossRef] [PubMed]

32. Guven, G.; Hilty, M.P.; Ince, C. Microcirculation: Physiology, Pathophysiology, and Clinical Application. Blood Purif. 2020, 49, 143-150. [CrossRef]

33. Ezaki, T.; Baluk, P.; Thurston, G.; La Barbara, A.; Woo, C.; McDonald, D.M. Time course of endothelial cell proliferation and microvascular remodeling in chronic inflammation. Am. J. Pathol. 2001, 158, 2043-2055. [CrossRef]

34. Ranucci, M.; Sitzia, C.; Baryshnikova, E.; Di Dedda, U.; Cardani, R.; Martelli, F.; Corsi Romanelli, M. COVID-19-Associated Coagulopathy: Biomarkers of Thrombin Generation and Fibrinolysis Leading the Outcome. J. Clin. Med. 2020, 9, 3487. [CrossRef] [PubMed]

35. Hilty, M.P.; Merz, T.M.; Hefti, U.; Ince, C.; Maggiorini, M.; Pichler Hefti, J. Recruitment of non-perfused sublingual capillaries increases microcirculatory oxygen extraction capacity throughout ascent to $7126 \mathrm{~m}$. J. Physiol. 2019, 597, 2623-2638. [CrossRef] [PubMed]

36. Parthasarathi, K.; Lipowsky, H.H. Capillary recruitment in response to tissue hypoxia and its dependence on red blood cell deformability. Am. J. Physiol. 1999, 277, H2145-H2157. [CrossRef] [PubMed]

37. Smadja, D.M.; Guerin, C.L.; Chocron, R.; Yatim, N.; Boussier, J.; Gendron, N.; Khider, L.; Hadjadj, J.; Goudot, G.; Debuc, B.; et al Angiopoietin-2 as a marker of endothelial activation is a good predictor factor for intensive care unit admission of COVID-19 patients. Angiogenesis 2020, 23, 611-620. [CrossRef]

38. Wichmann, D.; Sperhake, J.P.; Lütgehetmann, M.; Steurer, S.; Edler, C.; Heinemann, A.; Heinrich, F.; Mushumba, H.; Kniep, I.; Schröder, A.S.; et al. Autopsy Findings and Venous Thromboembolism in Patients With COVID-19: A Prospective Cohort Study. Ann. Intern. Med. 2020, 173, 268-277. [CrossRef]

39. Bryce, C.; Grimes, Z.; Pujadas, E.; Ahuja, S.; Beasley, M.B.; Albrecht, R.; Hernandez, T.; Stock, A.; Zhao, Z.; Chen, J.; et al. Pathophysiology of SARS-CoV-2: Targeting of endothelial cells renders a complex Disease with thrombotic microangiopathy and aberrant immune response. The Mount Sinai COVID-19 autopsy experience. medRxiv 2020. [CrossRef]

40. Ackermann, M.; Verleden, S.E.; Kuehnel, M.; Haverich, A.; Welte, T.; Laenger, F.; Vanstapel, A.; Werlein, C.; Stark, H.; Tzankov, A.; et al. Pulmonary Vascular Endothelialitis, Thrombosis, and Angiogenesis in COVID-19. N. Engl. J. Med. 2020, 383, 120-128. [CrossRef]

41. Menter, T.; Haslbauer, J.D.; Nienhold, R.; Savic, S.; Hopfer, H.; Deigendesch, N.; Frank, S.; Turek, D.; Willi, N.; Pargger, H.; et al Postmortem examination of COVID-19 patients reveals diffuse alveolar damage with severe capillary congestion and variegated findings in lungs and other organs suggesting vascular dysfunction. Histopathology 2020, 77, 198-209. [CrossRef] [PubMed]

42. Teuwen, L.A.; Geldhof, V.; Pasut, A.; Carmeliet, P. COVID-19: The vasculature unleashed. Nat. Rev. Immunol. 2020, 20, 389-391. [CrossRef] [PubMed]

43. Bermejo-Martin, J.F.; Almansa, R.; Torres, A.; González-Rivera, M.; Kelvin, D.J. COVID-19 as a cardiovascular disease: The potential role of chronic endothelial dysfunction. Cardiovasc. Res. 2020, 116, e132-e133. [CrossRef] [PubMed]

44. Varga, Z.; Flammer, A.J.; Steiger, P.; Haberecker, M.; Andermatt, R.; Zinkernagel, A.S.; Mehra, M.R.; Schuepbach, R.A.; Ruschitzka, F.; Moch, H. Endothelial cell infection and endotheliitis in COVID-19. Lancet 2020, 395, 1417-1418. [CrossRef]

45. Sardu, C.; Gambardella, J.; Morelli, M.B.; Wang, X.; Marfella, R.; Santulli, G. Hypertension, Thrombosis, Kidney Failure, and Diabetes: Is COVID-19 an Endothelial Disease? A Comprehensive Evaluation of Clinical and Basic Evidence. J. Clin. Med. 2020, 9 , 1417. [CrossRef]

46. Rovas, A.; Seidel, L.M.; Vink, H.; Pohlkötter, T.; Pavenstädt, H.; Ertmer, C.; Hessler, M.; Kümpers, P. Association of sublingual microcirculation parameters and endothelial glycocalyx dimensions in resuscitated sepsis. Crit. Care 2019, 23, 260. [CrossRef]

47. Park, J.F.; Banerjee, S.; Umar, S. In the eye of the storm: The right ventricle in COVID-19. Pulm. Circ. 2020, 10, 2045894020936660. [CrossRef] 
48. De Backer, D.; Creteur, J.; Dubois, M.J.; Sakr, Y.; Vincent, J.L. Microvascular alterations in patients with acute severe heart failure and cardiogenic shock. Am. Heart J. 2004, 147, 91-99. [CrossRef]

49. Jung, C.; Ferrari, M.; Rödiger, C.; Fritzenwanger, M.; Goebel, B.; Lauten, A.; Pfeifer, R.; Figulla, H.R. Evaluation of the sublingual microcirculation in cardiogenic shock. Clin. Hemorheol. Microcirc. 2009, 42, 141-148. [CrossRef] 